\title{
DEMARCANDO FRONTEIRAS MORAIS: UMA ANÁLISE DA CATEGORIA OLHO GRANDE EM SITUAÇÕES DE CONFLITO
}

\section{DEMARCATING MORAL BOUNDARIES: AN ANALYSIS OF THE EVIL EYE CATEGORY IN CONFLICT SITUATIONS}

\section{Gabriel Calil Maia Tardelli}

gabrielcmtardelli@gmail.com

Doutorando em Antropologia Social pela Universidade de Brasilia (UnB): pesquisador do Instituto de Estudos Comparados em Administração Institucional de Conflitos (INCT-InEAC) do Laboratório de Etnografia das Instituições e das Práticas de Poder (LEIPP-DAN-UnB) e do Laboratório e Grupo de Estudos em Relações Interétnicas (LAGERI/DAN/UnB).

Orcid: https://orcid.org/0000-0002-7252-0123

\section{RESUMO}

Os pescadores da Praia de Piratininga em Niterói (RJ) acusam de "olho grande" quem não compartilha os peixes capturados, quem prefere pescar individualmente, quem mantém segredos sobre pontos de pesca, quem se apropria dos espaços da praia de forma particularizada, quem ocupa as areias apenas para fins comerciais, desvinculados da atividade pesqueira. $\mathrm{O}$ olho grande é uma categoria acusatória e, ao mesmo tempo, um mecanismo de controle social, na medida em que expressa uma moralidade que se opõe à lógica individualista. Neste artigo, analiso algumas situações sociais nas quais essa categoria é acionada, de modo a tentar compreender os conflitos e as fronteiras morais que são demarcadas na praia por pescadores que exercem diferentes artes de pesca e por barraqueiros, homens e mulheres que vendem ali comidas e bebidas.

Palavras-chave: Pesca Artesanal. Fronteiras Morais. Administração de Conflitos.

\begin{abstract}
The fishermen of Piratininga Beach at Niterói (RJ) call "evil eye" those who don't share the fish caught, who prefer to fish individually, who keep secrets about fishing spots, make private fishing grounds or those who occupy the sand only for commercial purposes, unrelated to fishing. The evil eye is an accusatory category and, at the same time, a mechanism of social control, for it expresses a morality that is opposed to individualistic logic. In this article, I analyze some social situations in which this category is triggered, in order to understand the conflicts and moral boundaries that are demarcated on the shore by fishermen who carry different fishing gear and barraqueiros, that are men and women who share the place to sell food and beverage there.
\end{abstract}

Keywords: Artisanal Fishing. Moral boundaries. Conflict Management. 


\section{INTRODUÇÃO}

“Aqui só tem olho grande!", eis uma das frases que mais ouvi durante o meu trabalho de campo junto aos pescadores da Praia de Piratininga localizada no município de Niterói (RJ). À época, meu objeto foi construído em torno dos diferentes usos e apropriações do barracão de pesca, uma construção voltada tanto para operações ligadas às pescarias (consertos de embarcações, reparos de redes etc.) quanto para outras atividades sociais e econômicas (festejos, comercialização de pescado etc.). Tendo como foco o conflito que envolvia pescadores e barraqueiros, isto é, homens e mulheres que vendem comidas e bebidas nas areias da praia, notadamente durante o verão, observei que o "olho grande" era uma categoria de acusação acionada constantemente.

Trata-se de uma qualidade atribuída às seguintes pessoas e situações: quem não quer ter um companheiro de pesca para não ter que dividir o quinhão; quem não revela pesqueiros onde está "dando" peixe ou não mostra o que foi capturado ("cheio de segredo"); quem não distribui o pescado, seja com alguém que contribuiu nas operações de encalhar e desencalhar a embarcação, seja com alguém que pediu um peixe "para almoçar"; quem pesca eventualmente e apenas após constatar que alguém "se deu bem"; quem utiliza petrechos "não-tradicionais"; quem "faz comércio" na praia.

Os traços característicos dessa categoria acusatória podem ser encontrados em diferentes sociedades e em momentos distintos. Longe de querer buscar suas "origens" ou de traçar uma linha evolutiva marcada por continuísmos, utilizarei alguns contextos etnográficos a fim de contrastá-los com os sentidos que o olho grande assume no ethos dos pescadores de Piratininga, isto é, em suas atitudes emocionais (instintos e emoções dos indivíduos), "que determina qual valor uma comunidade atribuirá às várias satisfações ou insatisfações que os contextos da vida podem oferecer" (BATESON, 2008. p. 261). O ethos e o eidos - os aspectos cognitivos da personalidade dos indivíduos - compõem a noção de cultura proposta por Bateson (2008).

Dotado de uma dimensão moral, o ethos pode ser entendido como um sistema que orienta a maneira pela qual os grupos agem dentro de suas identidades coletivas a partir de certos valores normativos (LOBÃO, 2010). Penso, assim, que o ethos de um pescador é diferente daquele de um barraqueiro. Do mesmo modo, no que diz respeito ao eidos, relacionado aos aspectos cognitivos, mesmo que esses pescadores e barraqueiros usem e se apropriem de um mesmo espaço, este é representado de forma distinta por cada um desses grupos. Dessa forma, a partir de seus respectivos esquemas culturais, indivíduos e grupos demarcam fronteiras morais.

A meu ver, o olho grande, além de explicitar os conflitos que ocorrem na praia, pode ser interpretado como um mecanismo de controle social e de demarcação de fronteiras morais utilizado para combater determinadas insígnias da ideologia moderna (DUMONT, 1993). Nas situações que se desenrolam em Piratininga, a categoria se opõe ao individualismo daqueles que tentam recusar as relações hierárquicas - não no sentido de mando e desmando, mas no sentido dumontiano, isto é, na relação que as partes mantêm com um todo.

Com o auxílio da abordagem metodológica proposta por Gluckman (2010), descreverei, neste artigo, algumas situações sociais nas quais a categoria olho grande é acionada. Situações sociais são eventos que mantêm relações com outras situações sociais dentro de um sistema social (GLUCKMAN, 2010). Através da análise de eventos sucessivos, talvez possamos compreender quais são as configurações que marcam as relações conflituosas com as quais me deparei na Praia de Piratininga. 


\section{MUITOS SENTIDOS, POUCO CONSENSO}

O modelo arquitetônico do barracão, levando-se em conta as especificidades locais, pode ser observado em outras praias do litoral fluminense, como em Itaipu (KANT DE LIMA e PEREIRA, 1997; PESSANHA, 2003), em Maricá (MELLO e VOGEL, 2004) e na Ilha da Marambaia (MOTA, 2003). Igualmente, é possível encontrá-lo na Praia da Concha, localizada no estado do Espírito Santo (FILGUEIRAS, 2008). Em algumas localidades, como na Ilha da Marambaia, a palavra barracão dá lugar à categoria rancho, além de se empregar a técnica de construção do pau a pique.

O barracão de pesca deve ser entendido aqui como uma categoria local permeada por uma historicidade. Essa construção está localizada na Prai$n h a$, a parte menor da Praia de Piratininga - a parte maior é chamada de Praião -, formada por uma pequena enseada cercada por duas formações rochosas. Sujeito às intempéries marítimas (e políticas), o barracão fora derrubado e incendiado, motivo pelo qual os pescadores reergueram-no, improvisadamente, em diferentes períodos distintos. Os materiais utilizados são os mais variados possíveis: pedaços de madeira, restos de embarcações, bambus, palhas de coqueiros, telhas, cordames, fios etc.

É um espaço destinado a inúmeras finalidades ligadas direta ou indiretamente à pesca, a depender dos contextos e dos atores que dele se apropriam, sejam eles pescadores de arrasto de praia ou pescadores de rede de espera: armazenamento de embarcações, conserto de petrechos de pesca, limpeza e venda de pescado, reuniões da Associação Livre de Pesca e Amigos da Praia e Lagoa de Piratininga (Alpagoa), venda de comidas e bebidas, prosa, pernoitamento, festas de aniversário, confraternizações e brigas.

Figura 1 - Parte do barracão destinada ao armazenamento das canoas de "um tronco só"

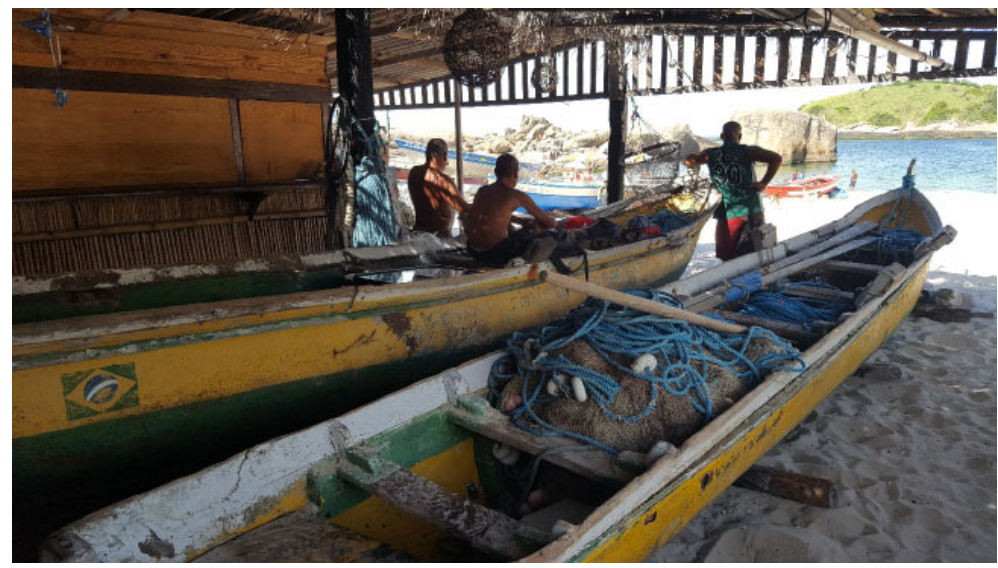

Fonte: Elaborada pelo autor.

Além dos pescadores, os barraqueiros também disputam entre si ou com os pescadores os espaços da praia próximos ao barracão ou na área onde este se encontra. Barraqueiro é a categoria utilizada para designar homens e mulheres que vendem comidas (peixe frito, batatafrita etc.) e bebidas (cervejas, refrigerantes e água) na praia, principalmente durante o verão, quando a praia recebe um maior número de banhistas e turistas. A palavra refere-se às barracas, mesas e cadeiras que são dispostas pelas areias da praia. Para um observador desatento, é praticamente impossível enxergar as linhas imaginárias que separam a mobília de um barraqueiro da mobília de outro. No entanto, esses móveis possuem inscrições que identificam seus respectivos donos, além de não estarem organizados de maneira aleatória; ao contrário, estão circunscritos a espaços específicos, previamente acordados de maneira explícita ou tácita entre os próprios comerciantes. 
Infelizmente, como não estabeleci laços mais estreitos com os barraqueiros, os dados a respeito deles foram construídos a partir do universo dos pescadores. Todavia, através das observações realizadas na praia, pude constatar como se desenrolam algumas relações sociais que envolvem os dois grupos de atores.

O conflito entre pescadores e barraqueiros é da mesma ordem do conflito interno aos pescadores: todos disputam o espaço onde está situado o barracão de pesca ou a área que o circunda. Mas os significados atribuídos ao objeto em disputa, assim como as justificativas adotadas para ocupá-lo são divergentes. Alguns usam o espaço coletivamente; outros, apropriam-se de maneira particularizada. $\mathrm{O}$ barracão foi construído por pescadores e para a pesca; mas, como alguns pescadores "fazem comércio" naquela construção, alguns barraqueiros acharam-se no direito de levantar construções anexas ao barracão, onde guardam suas mesas, cadeiras e barracas e, em alguns casos, dispõem de fogões e geladeiras.

No entanto, embora haja uma oposição entre barraqueiros (de fora) e pescadores (de dentro), essa oposição por contraste precisa ser relativizada, uma vez que aqueles que colocam barracas na praia mantêm, frequentemente, laços de parentesco e/ou vizinhança com aqueles que vivem da pesca. Além disso, alguns pescadores também "fazem comércio" enquanto complemento ou alternativa econômica à atividade pesqueira. Nesse caso, um mesmo espaço pode servir para guardar redes e canoas e, paralelamente, para vendes peixes, batata frita e cervejas. Como nem todos os barraqueiros possuem um "barraco" e uma cozinha, alguns pescadores, inclusive, permitem que aqueles utilizem seus fogões e refrigeradores. Por fim, ainda que pescadores de diferentes modalidades de pesca disputem os espaços da praia entre si e com os barraqueiros, essas pessoas mantêm relações amistosas em outros espaços de socialização, a despeito da deflagração de conflitos.

Sob essa perspectiva, em conformidade com os respectivos interesses e ethos (BATESON, 2008) desses atores, muitos são os sentidos atribuídos ao barracão de pesca. Para uns, é um "espaço de pesca da pescaria artesanal tradicional e comunitária", um locus de "resistência" às investidas da especulação imobiliária e da "modernização"; para outros, é um "ganha pão", um "bar/restaurante" onde se pode "fazer comércio", vendendo comidas e bebidas para os banhistas e turistas que chegam à praia; pode ser, ainda, a "sede da associação de pesca", um "espaço público" ou uma "favela" - no sentido pejorativo do termo.

Figura 2 - Pagode no barracão de pesca.

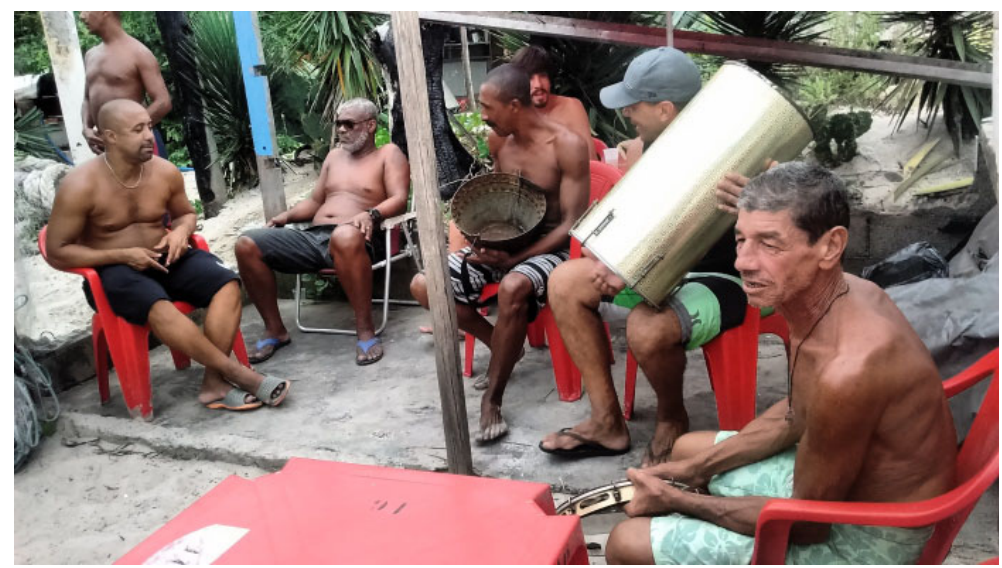

Fonte: Elaborada pelo autor. 
Para o único pescador que ainda pratica a pesca de arrasto de praia, o barracão é um "acampamento", porque os pescadores devem se adaptar à "natureza", precisam "evoluir", não ficar parados no tempo. A pesca de canoa é "tradicional" porque se utiliza de elementos do meio ambiente (o tronco para fazer a canoa; o murici que tinge as redes) e domina os movimentos desse mesmo meio (luas, marés etc.). O interesse em ocupar o espaço reside na "resistência", na preservação de um "núcleo de pesca artesanal", em respeito à memória dos mais velhos.

Quem se opõe à essa concepção é classificado por ele como "olho grande", pois não pensa na coletividade, age individualmente, visando apenas a obtenção de bens materiais. Contraditoriamente, ele defende a necessidade de sua companheira possuir uma "cantina" (ou bar/restaurante, segundo os discordantes) em uma área do barracão, seja para resguardar suas canoas do avanço dos barraqueiros pelas extensões da praia, seja como forma de se auferir uma renda complementar, que contribua para a manutenção da "tradição". Nesse caso, o material improvisado do "acampamento" vai dando lugar à alvenaria, à fixação no espaço: pisos cimentados e paredes com tijolos.

O problema é que a autoridade que ele possui enquanto mestre não se confunde com a disputa pelo poder em face do barracão. Eis um dos paradoxos constatados. Dentro ou fora da canoa, o mestre não está investido de poder, não lhe foi conferida a capacidade de mandar e desmandar nos demais membros da companha, uma vez que o princípio hierárquico inscrito nos lugares da embarcação diz respeito à relação do todo com as partes que compõem o todo, não a relações verticais de mando e obediência (DUMONT, 1993). O prestígio que o mestre possui enquanto porta-voz do grupo, por suas qualidades e pelo seu reconhecimento (os saberes que domina, o aval dos mais velhos etc.), não representa uma concentração de poder (CLASTRES, 2015a). O mestre encontra-se impotente diante da inobservância das "regras".

Figura 3 - Venda de comidas e bebidas no barracão

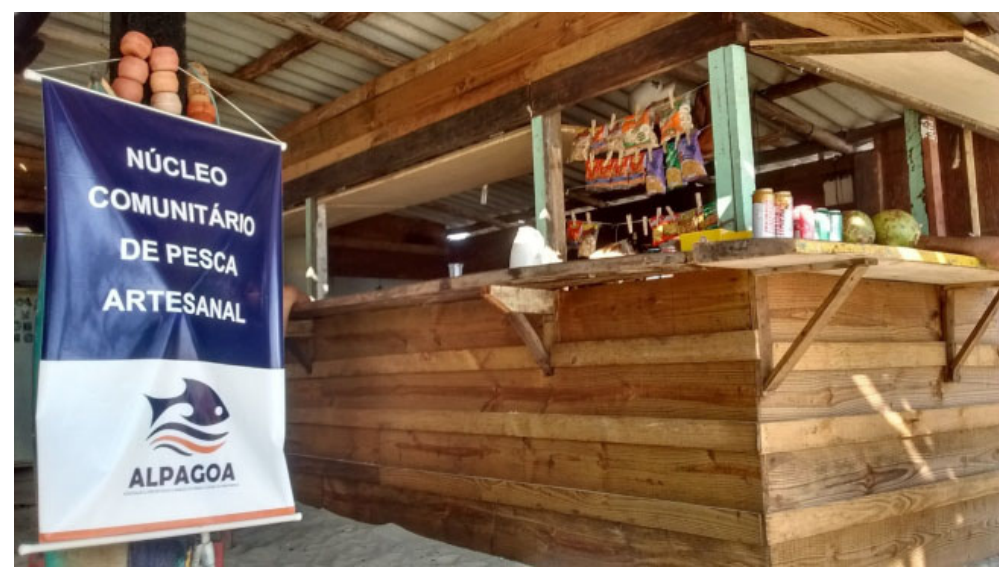

Fonte: Elaborada pelo autor.

Para um dos pescadores que pratica a rede de espera, o barracão é um "coração de mãe", pois está aberto a todo mundo, ainda que ele tenha colocado um portão com cadeado e que tenha se apropriado de maneira particularizada de uma área que correspondia a mais de oito pescadores. Ele apenas coloca "ordem" e mantém tudo "limpo". Acredita que sua ocupação está legitimada pela posse da carteira de pesca, independentemente de ter trazido para o espaço o "pessoal do Cafubá", que, além de não ser constituído por pescadores, "ninguém conhecia". Assim como o pescador mencionado anteriormente, ele também "faz comércio" no barracão, embora tenha criticado aquele em algumas 
ocasiões. Mas ambos parecem concordar nesse aspecto, já que relacionam a venda de comidas e bebidas à "sobrevivência na beira na praia".

Os barraqueiros, por sua vez, também veem aquele espaço como uma oportunidade econômica. Se os pescadores podem utilizar o espaço para fins comerciais, eles também o podem. Não são "pescadores", mas são "conhecidos", "parentes", "vizinhos" e "amigos". Entretanto, não permanecem na praia durante todo o ano, mas apenas quando há um interesse do ponto de vista pecuniário. Sua apropriação é particularizada, voltada para uma única finalidade (o comércio) e está sujeita a negociações de viés mercantil, embora, em alguma medida, também estejam inseridos em laços de reciprocidade que norteiam as relações sociais dos pescadores locais.

Figura 4 - Limpeza e venda do pescado no barracão de pesca

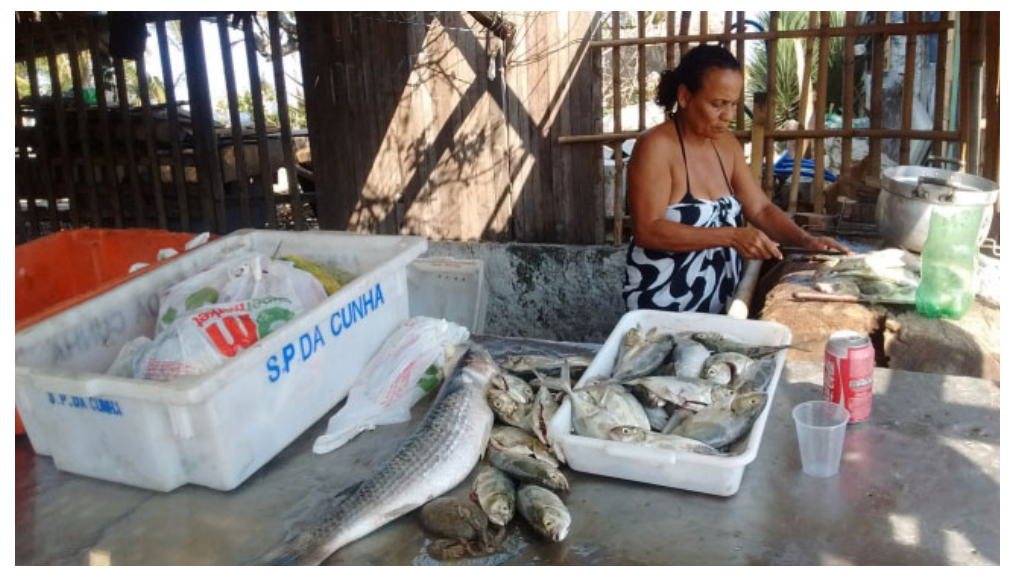

Fonte: Elaborada pelo autor.

Dessa forma, a partir da memória vivida dos pescadores e das minhas observações, pude constatar que as reconfigurações pelas quais o barracão passou estão atreladas às necessidades, aos interesses e aos sentidos atribuídos a ele em diferentes contextos por diferentes atores (TARDELLI, 2017). Cada interesse e cada sentido encontra correspondência em formas diferenciadas de ocupação e no discurso utilizado para legitimá-la. Temos, portanto, uma disputa política de poder, na medida em que a capacidade de definir significados põe em xeque tanto o significado dos objetos quanto os próprios objetos e sua posição estrutural: os sujeitos "deixam de ser escravos de seus conceitos para se tornarem seus senhores" (SAHLINS, 1990, p. 11).

Naquela localidade, o conflito aparece como forma estruturante das relações sociais (SIMMEL, 1983; GLUCKMAN, 2010; 2011). Lá, a variação entre a tratabilidade e a intratabilidade do conflito acompanha a alternância sazonal entre inverno e verão e suas respectivas morfologias. Embora as disputas aparentemente estejam resolvidas durante o inverno, quando as clivagens parecem diminuir - período durante o qual a praia é "lugar de pescador", isto é, quando poucos "fazem comércio" -irrompem novamente durante o verão.

Mais do que um drama social (TURNER, 2008), o conflito em Piratininga apresenta-se como um conflito intratável (PUTNAM e WONDOLLECK, 2003; LOBÃO, 2010). Ele reproduz não somente uma alternância sazonal, mas uma forma de sociabilidade que permeia a estrutura do grupo. O conflito é reforçado constantemente, na medida em que os contendores representam de maneira diferente o objeto em disputa. Além disso, há sempre um impasse quanto às regras estabelecidas. E, mesmo que haja uma mudança dos atores $\mathrm{e}$ do objeto, o conflito parece inexorável. 


\section{O OLHO GRANDE EM AÇÃO}

Para que possamos compreender o sentido da categoria olho grande, analisarei, primeiramente, uma situação social que se mostrou emblemática durante o trabalho de campo: os incêndios que acometeram o barracão de pesca.

O primeiro afetara um quiosque de sapê, localizado na parte externa atrás do barracão. A construção era utilizada temporária e especialmente para que um velho pescador aposentado, pudesse reformar uma canoa. Já o segundo incêndio ocorrera em 2014 e atingira o barracão propriamente dito. Em ambos, perderam-se embarcações, redes, remos e outros petrechos, além de ter provocado a morte de dois cães que ficavam pelas areias da praia.

As tensões acentuaram-se após o segundo incêndio. Pouquíssimos pescadores mobilizaram-se para retirar as cinzas e os escombros. Nos bastidores, à boca miúda, suspeitava-se que o fogo havia sido provocado por pescadores locais. Embriagados, eles mesmos teriam revelado a autoria, motivados pela insatisfação com a maneira pela qual o espaço era utilizado. Mas ninguém os acusou publicamente; eles continuam a fazer parte do grupo e a frequentar os mesmos espaços de socialização. Para quem perdeu seus bens materiais, tudo não passou de inveja e "olho grande".

O pescador de arrasto de praia sustenta que o conflito existente na praia ocorre em função do olho grande. Após reerguer o barracão praticamente sozinho, seu objetivo era manter a divisão anterior do espaço. Todavia, um pescador, "de olho grande", apropriou-se de uma parte que antes cabia a mais de oitos membros do grupo. Apesar de permitir que outras pessoas armazenem ali seus petrechos, tem utilizado esse segmento do barracão para "fazer comércio", trazendo, inclusive, um "pessoal de fora", o que tem gerado mais intrigas e discórdias. Não obstante, o mesmo pescador, quando mergulha para catar mexilhão, faz uso de um compressor (instrumento "não-tradicional"), que the possibilita recolher uma quantidade muito superior daquele molusco, se comparado com quem mergulha de apneia.

O meu intuito não é empreender uma investigação criminal, a fim de desvendar supostas "causas" e eventuais incendiários. Enfoco nos incêndios porque, a meu ver, estes podem ser lidos como eventos que alteraram a estrutura local de significados (SAHLINS, 1990) e, ao mesmo tempo, como eventos críticos que ampliam e põem em relevo o que já é usual naquela estrutura (DAS, 1995; PEIRANO, 2002). Nesse sentido, o incêndio trouxe mudanças estruturais que se refletem tanto nas representações do grupo a respeito daquela construção ("isso aqui parece uma favela") quanto nas concertações entre os interessados em ocupar um espaço na praia: após o incêndio, o barracão adquiriu uma nova repartição, além de os barraqueiros terem levantado construções anexas a ele ("barracos").

Igualmente, os pescadores enunciam uma série de eventos ligados à "modernidade" que trouxeram mudanças substanciais para suas vidas ao longo do tempo: o loteamento do bairro de Piratininga, a abertura do Canal de Camboatá pela empresa Veplan Imobiliária, a pavimentação da Rodovia Amaral Peixoto (RJ-106), a construção da Reserva Extrativista Marinha (Resex), a

54 especulação imobiliária, o surgimento do nylon plástico, o avanço tecnológico, a "globalização". Distantes da falsa ideia de uma vida insular em um suposto estado de pureza, os pescadores vivenciam inúmeros processos, cujos interesses dos participantes nem sempre são convergentes.

Ademais, a categoria olho grande é invocada em outras situações sociais. Um pescador saiu mais cedo do que os outros e voltou com o barco 
cheio de peixes. Ao ser indagado sobre o ponto de pesca onde realizou a pescaria, preferiu manter segredo. Foi acusado de ser olho grande. Outro pescador recusou a ajuda que lhe ofereceram para desencalhar a embarcação. Preferiu realizar a operação sozinho. Como ele é olho grande, provavelmente não queria ter que retribuir o auxílio com um punhado de peixes. Em uma terceira situação, um pescador que limpava e vendia o pescado na beira da praia se negou a dar alguns peixes a um "conhecido" para "inteirar no almoço". Mais um olho grande.

Figura 5 - Operação de encalhar a canoa

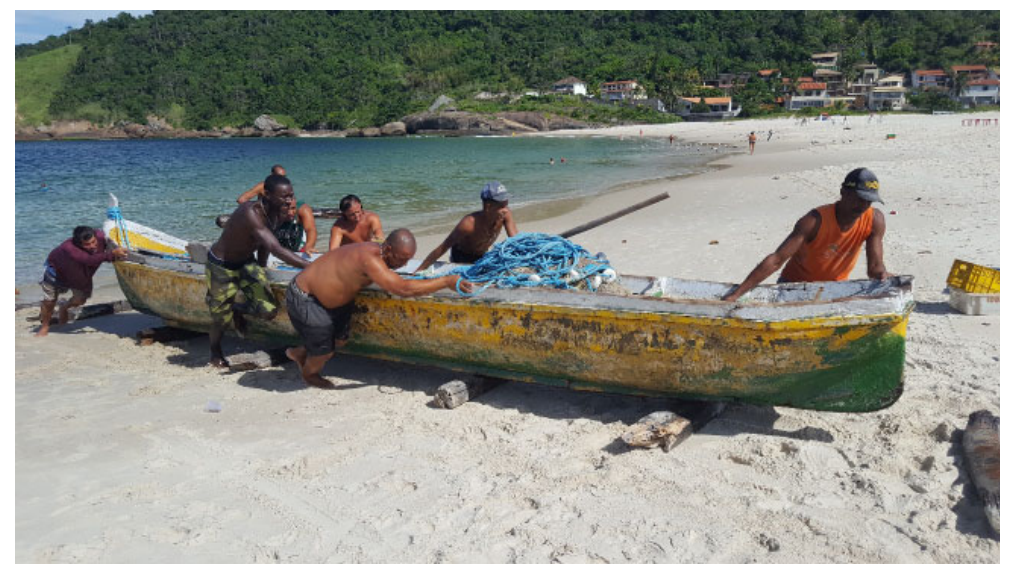

Fonte: Elaborada pelo autor.

Galheta, Praião e Zé Mundrongo são nomes de pesqueiros, assim como Ferrinho e Passarinho. Apesar de não haver uma regra que proíba que as redes sejam colocadas nesses pontos, o fato é que alguns pescadores são mais ciosos de alguns lugares específicos. Dessa forma, se estiver "matando" muito peixe em um pesqueiro onde tem o hábito de pôr a rede, chamará de olho grande aquele que quiser usufruir do mesmo lugar. Em um samba, por exemplo, o compositor, amigo dos pescadores, fez galhofa com um pescador que quer colocar a rede em todos os pesqueiros que estão "dando" peixe:

Se eu vou na Galheta, ele vai

Se eu vou no Praião, ele vem

Até lá no Zé Mundrongo

Ele já está também.

$\mathrm{Na}$ beira da praia, enquanto limpavam e vendiam os peixes capturados pela manhã, as relações jocosas continuam a explicitar essas tensões; dessa vez, ao som de uma marchinha batucada nos bordos de um barco:

Vai lá, Valmir,

Que a hora é essa!

$\mathrm{O}$ Catiquinho matou lula à beça.

O Catiquinho quando pesca olho-de-cão,

O Catiquinho arruma confusão.

O olho grande é motivo de infortúnios, inclusive de deslocamentos nas posições hierárquicas e na queda de prestígio. Um homem deixou de ser dono e mestre de sua própria companha para se tornar membro da companha de outrem. Tudo teria começado a partir do momento em que "cresceu o olho; depois disso, nada mais deu certo". Certo dia fez o arrasto, sem, contudo, obter êxito. No dia seguinte, ao tentar novamente, encheu muitas caixas de peixe. No entanto, distribuiu injustamente as capturas entre os membros da equipe. Seus 
dias de glória estavam prestes a terminar: semanas depois, sua rede rasgou ao ficar presa em uma pedra.

\section{DOS LIMITES DAS FRONTEIRAS MORAIS}

Durante o trabalho de campo que realizara em Piratininga na década de 1980, Silva (1988, p. 22) analisou a concepção de "natureza" dos pescadores de Piratininga. Para ela, tratava-se de uma visão holista, uma vez que a natureza seria um grande "conjunto englobador". Nas representações dos pescadores, "o curso dos acontecimentos do plano social pode ser, então, facilitado, dificultado ou impedido pelos fenômenos naturais". Períodos de fartura ou infortúnios "são atribuídos à maior ou menor generosidade natural" (SILVA, 1988).

Penso que o olho grande compartilha com essa noção de natureza de uma mesma economia moral. Ainda que a categoria articule juízos morais com a atribuição de responsabilidade pessoal (FILGUEIRAS, 2009), vinculadas a ações concretas, quando assume o sentido de infortúnio pode ser relacionada a "forças naturais" ou imateriais.

Entre os pescadores da Praia da Concha, na Barra do Jucu (ES), Filgueiras $(2009 ; 2013)$ identificou a mesma categoria sendo utilizada em contextos quase idênticos e com significados muito similares aos que pude observar em Piratininga. Na praia capixaba, um pescador é acusado de olho grande por não repartir adequadamente os peixes, assim como as pescarias de arrasto são consideradas de olho grande quando contrastadas com as de linha. No verão ("tempo quente"), em oposição ao inverno ("tempo frio"), o "olho cresce", aumentando as disputas pelos espaços da praia.

Em alguns bairros periféricos de Porto Alegre, Cláudia Fonseca observou que a expressão "olho grande" "serve para explicar ao mesmo tempo os empreendimentos ambiciosos e seu fracasso" (FONSECA, 2004, p. 108). Como em Piratininga, ele pode designar tanto ambições desmesuradas quanto forças externas que levam os ambiciosos a fracassar-lembrem-se do pescador desafortunado que, ao crescer o olho, não obteve mais êxitos nas pescarias. No primeiro caso, o adjetivo recai sobre um indivíduo; no segundo, torna-se impessoal e estende-se para todo o grupo ("aqui só tem olho grande").

O verbete "olho grande" consta no Dicionário do folclore brasileiro, de Luís da Câmara Cascudo. Sinônimo de "olho mau, passível de irradiação maléfica", trata-se de "uma das maiores prevenções alimentadas pela superstição popular na Amazônia, como aliás em todo o Brasil" (CASCUDO, 1972, p. 613). A presença de rituais preventivos ou capazes de reverter os efeitos do "olho grande" foi constatada, igualmente, em religiões de matriz africana, como na umbanda (BIRMAN, 1980) e no candomblé (MAGGIE, 2001).

Do mesmo modo, a categoria olho grande encontra correspondências em estudos sobre o que Mauss e Hubert (2013) designaram de maneira abrangente como "magia". Eles teceram observações sobre o papel que o órgão da visão desempenha na identificação do agente do rito mágico, isto é, o "mágico". "Em toda parte há", conforme os autores,"pessoas cujo olhar vivo, nervoso, pisco e falso, o 'mau olhado', em suma, faz que elas sejam temidas e malvistas" (MAUSS e HUBERT, 2013, p. 64).

Como um estigma, o mau-olhado pode acompanhar uma pessoa desde a tenra idade, é o que Lévy-Bruhl (2008) observara em relação às Kiliba (Kiliba-Kitabwa), crianças que habitavam o então Congo belga e cujos dentes superiores nasciam primeiro. Eram elas que provocavam as desgraças que 
aconteciam na aldeia, motivo pela qual frequentemente eram mortas, sendo atiradas na água ou sendo expostas às feras. Caso a criança permanecesse viva, seu pai seria alvo de reprovações dos membros da família. Entre os warega, por outro lado, as crianças não eram sacrificadas, mas tratadas socialmente como párias.

Do mesmo modo, o feiticeiro, que muitas vezes ignorava sua condição de feiticeiro, servia de alojamento para um princípio maligno - constatado materialmente através da autópsia - que agia como o mau-olhado: "Ele espalha a desgraça ao redor de si no grupo social" (LÉVY-BRUHL, 2008, p. 247).

Em Piratininga, o olho grande não necessariamente sabe que é classificado como tal, uma vez que, em geral, essa acusação não é feita diretamente, mas, sim, nos bastidores e enquanto uma reclamação segredada a terceiros. Além disso, a pessoa olho grande não é temida, não se torna um pária ou é morta pela sua condição. Como observei, essa identidade contrastiva é construída em situações conflituosas, o que não impede que acusador e acusado mantenham relações cordiais e laços de reciprocidade em outras situações sociais.

Entre os Azande, o conceito de bruxaria fornecia não somente uma "filosofia da natureza", através da qual era possível explicar a relação entre os homens e o infortúnio, mas também "um sistema de valores que regula a conduta humana" (EVANS-PRITCHARD, 2005, p. 49). Todavia, se um tabu fosse quebrado, a bruxaria não necessariamente seria considerada como a causa do fracasso; salvo se houvesse morte após a violação do interdito. Assim, embora muitos infortúnios fossem atribuídos à bruxaria, ela não era a causa de todos os males.

As pessoas que infringiam as regras de conduta local eram mais frequentemente acusadas de bruxaria, ou seja, "os bruxos tendem a ser aqueles cujo comportamento afasta-se mais das exigências sociais" (EVANS-PRITCHARD, 2005, p. 79). Isso porque "é no idioma da bruxaria que os Azande exprimem as regras morais que escapam à esfera da lei civil e criminal" (EVANS-PRITCHARD, 2005, p. 77). Entretanto, a posição de um bruxo não se assemelhava à daquele que, em nossa sociedade, é considerado como "criminoso". Sob essa perspectiva, a bruxaria tinha um caráter duplo: tanto podia fomentar e acentuar conflitos quanto podia controlar demonstrações de hostilidade.

Entre os Azande, as categorias acusatórias eram acionadas constantemente entre parentes e vizinhos que mantinham relações hostis, baseadas em invejas, ciúmes e intrigas. Esses, na verdade, como o próprio Evans-Pritchard argumenta, eram os elementos que estavam por trás da bruxaria. Nesse sentido, acusava-se de bruxo aquele ou aquela com quem se tinha uma desavença: um inimigo, alguém que the roubou a esposa ou que não pagou o que the era devido. Quanto mais próximos, maiores as tensões; “(...) quando essa proximidade não é atenuada por sentimentos de parentesco ou tornada irrelevante por distinções de idade, sexo ou classe" (EVANS-PRITCHARD, 2005, p. 75).

Herzfeld (1981) adotou uma abordagem semiótica para compreender os significados do evil eye em uma aldeia grega. Atentando para moralidades locais, ele tratou o sistema simbólico formal como um código a partir do qual os comportamentos individuais - aqueles de acusadores e acusados - derivam seu significado. O mau-olhado pode ser parte desse sistema de signicação.

Nessa perspectiva, a matriz conceitual das crenças do mau-olhado se estende para além do símbolo do próprio olho. Assim, é possível perceber o evil eye como um símbolo de trasgressões de limites. Na pequena aldeia de Pefko, por exemplo, eram suspeitas as pessoas que possuíam olhos azuis e "felinos" (gatthika, isto é, inclinados), o que não ocorria na Creta Ocidental e na bacia de 
Haliakmon da Macedônia. O olho "estranho" demarcava, portanto, as fronteiras sociais entre as pessoas "de dentro" e "de fora" (HERZFELD, 1981).

Expressões de uma moralidade que condena a "fraqueza" e a "esquisitice", o "olho incomun" ou a negação da sorte eram "metáforas para uma incapacidade de se conformar às normas de interação social da aldeia", segundo Herzfeld (1981, p. 570, tradução livre). Para ele, o foco no simbolismo das fronteitas sociais permite "tratar o mau-olhado como um dos muitos possíveis símbolos da marginalidade social e não exige a priori que ele represente exatamente o mesmo tipo de marginalidade sempre que ocorrer".

O olho grande, em Piratininga, demarca as fronteiras morais entre as pessoas de dentro e de fora. Como vimos, os barraqueiros, geralmente, são moradores do bairro de Piratininga, mantendo, em alguns casos, vínculos de parentesco e/ou vizinhança com pescadores. Todavia, mesmo sendo considerados como "conhecidos", "parentes" ou "vizinhos", são classificados como "de fora". Isso porque de fora não se refere apenas àqueles que não pertencem a Piratininga, mas também àqueles que não são pescadores (como os compradores habituais do pescado) ou que se encontram em disputa com os pescadores (como os barraqueiros). Por outro lado, a acusação não recai somente naqueles que são de fora, uma vez que os próprios pescadores podem ser acusados de olho grande.

Assim como entre os Azande, entre os pescadores de Piratininga a categoria olho grande explicita um sistema de valores que regula e orienta as ações daquelas pessoas. Nesse caso, são acusados de olho grande "amigos", "parentes", "vizinhos" que não observam as regras locais, isto é, que transgridem os limites das fronteiras morais. Mas não se trata meramente de uma inobservância de regras. Isso porque a acusação é antecedida por ciúmes, intrigas e desavenças que não dizem respeito necessariamente à situação durante a qual alguém é acusado de ser olho grande.

Aquele que é acusado também não é considerado um "bruxo", um "criminoso" ou é necessariamente marginalizado pelo grupo. Ademais, nem todos os infortúnios são atribuídos ao "olho grande"; depende do contexto e das pessoas envolvidas. Pelo que pude observar, a categoria é acionada em contextos de tensões e disputas - que são constantes na praia.

\section{ALGUMAS CONSIDERAÇÕES FINAIS}

Em Piratininga, como entre os Azande, o acusador e o acusado mantêm relações hostis, marcadas pela proximidade geográfica e social e baseadas em ciúmes e intrigas. Tal hostilidade, contudo, não impossibilita que esses mesmos atores mantenham, paralelamente, relações amistosas. Isso porque, através da escolha situacional (GLUCKMAN, 2010), um indivíduo pode participar de diferentes grupos, ainda que aparentemente contraditórios.

O olho grande é a expressão de uma moralidade que condena determinados ethos cujos valores correspondem ao que Dumont (1993) chamou de "ideologia moderna". Dessa forma, é tanto uma categoria acusatória quanto um mecanismo de controle social. Como um símbolo de transgressão de limites, o olho grande demarca as fronteiras morais que estão definidas naquela praia. Nas situações que ali se desenrolam, a categoria se opõe ao individualismo daqueles que tentam recusar as relações hierárquicas, subvertendo os papeis socialmente estabelecidos.

O sujeito "olho grande" é aquele que prefere pescar individualmente para não ter que compartilhar a captura, além de manter segredos a respeito de 
pesqueiros ou da quantidade e das espécies que capturou. Ele também não é solidário com quem lhe ajudou ou com quem lhe pede um punhado de peixe. O "olho grande" utiliza instrumentos "não-tradicionais" e "faz comércio" na praia, ao invés de se dedicar à pescaria.

Sob essa perspectiva, essa categoria acusatória insurge-se contra as insígnias da ideologia moderna (DUMONT, 1993), como a trinca "propriedade" (formas particularizadas de apropriação do espaço), "liberdade" (no sentido de uma economia liberal baseada na competitividade) e "igualdade" (quando se tenta eliminar as marcas distintivas dos papeis sociais). O indivíduo, entendido enquanto ideia-valor do pensamento moderno (DUMONT, 1993), recusa as atividades coletivas, assim como o compartilhamento de experiências e informações. O princípio individualista é, pois, uma afronta às regras estabelecidas localmente.

A despeito dos "avanços" tecnológicos, do "progresso" e do "desenvolvimento", as sociedades contemporâneas não estão totalmente submersas na ideologia moderna, do mesmo modo que a economia de mercado não engolfou todas as relações sociais (POLANYI, 2012; CLASTRES, 2015b). Nesse sentido, os usos e apropriações dos espaços em Piratininga podem ser entendidos como o "resultado de uma história em cujo transcurso modernidade e não modernidade ou, mais exatamente, as ideias-valores individualistas e suas contrárias combinam-se intimamente" (DUMONT, 1993, p. 31).

Assim, os paradigmas holista e individualista não estão necessariamente apartados. A pesca de rede de espera não prescinde de vínculos de reciprocidade, de uma rede de relações de parentesco, vizinhança, amizade e compadrio. Do mesmo modo, o barracão não está reduzido simplesmente a uma propriedade, passível de negociação na economia de mercado (TARDELLI, 2017).

Os pescadores de arrasto de praia ou de rede de espera não se posicionam diretamente contra o "fazer comércio". Ao contrário, para muitos, é a venda de comidas e bebidas na praia que possibilita a continuidade das pescarias, uma vez que, frequentemente, os rendimentos obtidos com a pesca são insuficientes para o sustento de suas famílias. Poucos são os que se dedicam exclusivamente à atividade pesqueira. Por outro lado, e de maneira paradoxal, quando os espaços da praia são apropriados prioritariamente para fins comerciais, eles se sentem ameaçados, uma vez que são colocadas em xeque as condições de possibilidade de se reproduzirem social e culturalmente enquanto pescadores artesanais.

\section{NOTAS}

${ }^{1}$ Este artigo é uma versão modificada de um trabalho apresentado na $31^{\text {a }}$ Reunião Brasileira de Antropologia, realizada entre os dias 09 e 12 de dezembro de 2018, Brasília/DF.

${ }^{2}$ Quinhão: aquilo que cada pescador recebe pela participação em uma pescaria; parte do rendimento obtido com a pesca.

${ }^{3}$ Encalhar é a operação de tirar a embarcação do mar e empurrá-la para a areia; desencalhar é a operação inversa.

${ }^{4}$ Essa técnica também é conhecida como taipa de mão, taipa de sopapo ou taipa de sebe. É uma técnica de construção que consiste no entrelaçamento de madeiras verticais fixadas no solo, com vigas horizontais (geralmente de bambu), amarradas entre si por cipós, dando origem a um grande painel perfurado que, após ter os vãos preenchidos com barro, transforma-se em parede.

${ }^{5}$ Arrasto de praia (ou arrastão): arte de pesca que utiliza as tradicionais canoas de "um 
tronco só"; subdivide-se nas modalidades do lanço à sorte e do cerco com vigia.

${ }^{6}$ Rede de espera: arte de pesca praticada na praia; é realizada por uma ou duas pessoas e consiste em deixar a rede esticada no fundo, fixa em ambos os extremos por âncoras e sinalizada por boias e, às vezes, por duas bandeiras. A rede é recolhida no início do dia para se tirar a captura (cobrar a rede). Se o mar estiver em boas condições, colocam-na novamente. Mas, se tiver pouco peixe, deslocam a rede para outro local; havendo previsão de temporal, retira-se a rede da água.

${ }^{7}$ Geralmente, são moradores do bairro de Piratininga ou de localidades próximas, mantendo, em alguns casos, vínculos de parentesco e/ou vizinhança com os pescadores locais.

${ }^{8}$ Moradores de bairros mais longínquos ou de outras cidades que vêm para a praia nos fins de semana e feriados, principalmente durante o verão.

9 Mestre: membro da companha responsável pela pescaria; quem decide como será executada a pescaria e determina o ritmo e a velocidade a ser imprimida pela canoa; o responsável pela distribuição e comercialização do produto.

${ }^{10}$ Companha: grupo de pescadores que se reúne para realizar as pescarias de arrasto de praia; organização dotada de relações hierárquicas e de uma divisão social do trabalho; o mesmo que equipe.

11 Turma e pessoal são as categorias mais utilizadas pelos pescadores de Piratininga para se referir àqueles que são de fora. Acompanhadas de uma localidade (Jurujuba, Cafubá, favela etc.) e pronunciadas em situações de oposição em relação a normas e comportamentos locais, adquirem uma conotação negativa ("A turma da Jurujuba vem, raspa o marisco e a pedra fica lisa. Ai, o peixe vai abandonando, não tem o que comer"). Cafubá é um bairro da Região Oceânica de Niterói que possui limites com o bairro de Piratininga, assim como as localidades de São Francisco, Jurujuba, Camboinhas, Itaipu e Jacaré.

12 Não presenciei nenhuma contenda em que um oponente acusava o outro, diretamente, como olho grande. Essa categoria era sempre pronunciada nos bastidores, à boca miúda, em tom de reprovação, seja em diálogos com terceiros, seja em conversas com o antropólogo.

${ }^{13}$ Nylon plástico é o material utilizado nas redes de pesca industrializadas. Estas são percebidas negativamente por alguns pescadores como mais "modernas" e, portanto, menos "tradicionais", uma vez que podem ser compradas "prontas", dispensando o saber naturalístico que norteia a confecção e o reparo dos petrechos de pesca "artesanais".

14 Dono: membro da companha; proprietário do conjunto de aparelhos que compõe a pescaria.

\section{REFERÊNCIAS BIBLIOGRÁFICAS}

BATESON, Gregory. Naven: um exame dos problemas sugeridos por um retrato compósito da cultura de uma tribo na Nova Guiné, desenhado a partir de três perspectivas. 2. ed. São Paulo: Editora da Universidade de São Paulo, 2008.

BIRMAN, Patrícia. Feitiço, carrego e olho grande, os males do Brasil são: estudo de um centro umbandista numa favela do Rio de Janeiro. 1980. Dissertação (Mestrado em Antropologia Social) - Museu Nacional, Universidade Federal do Rio de Janeiro, Rio de Janeiro. 1980.

CASCUDO, Luís da Câmara. Dicionário do folclore brasileiro: J-Z. 3. ed. Instituto Nacional do Livro: Brasília, 1972.

CLASTRES, Pierre. Sociedade contra o estado. 2. reimp. São Paulo: Cosac Naify, 2015a.

. A economia primitiva. In: Arqueologia da violência - pesquisas de antropologia política. 3. ed. São Paulo: Cosac Naify, 2015 b. 
DAS, Veena. Critical Events. An Anthropological Perspective on Contemporary India. Delhi: Oxford University Press, 1995.

DUMONT, Louis. $O$ individualismo: uma perspectiva antropológica da ideologia moderna. Rio de Janeiro: Rocco, 1993.

EVANS-PRITCHARD, E. E. Bruxaria, oráculos e magia entre os Azande. Rio de Janeiro: Jorge Zahar Ed., 2005.

FONSECA, Claudia. Família, fofoca e honra: etnografia de relações de gênero e violência em grupos populares. 2. ed. Porto Alegre: Editora da UFRGS, 2004.

FILGUEIRAS, Márcio de Paula. Entre pescarias e meio ambiente: alguns usos e representações sobre os barracões da Praia da Concha (Vila Velha-ES). In: Reunião Brasileira de Antropologia, 26a , 2008. Porto Seguro, Bahia. Anais... Porto Seguro, 2008.

. Tempo e sociedade entre os pescadores da Barra do Jucu/ES. SINAIS Revista Eletrônica - Ciências Sociais, UFES, n. 5, v. 1, set., p. 145-169, 2009.

. Nota sobre o lugar do conflito para o pesquisador e para o pesquisado. Simbiótica, UFES, v. 1, n. 3, jun. 2013.

GLUCKMAN, Max. Análise de uma situação social na Zululândia moderna. In. FELDMAN-BIANCO, Bela (org.). Antropologia das sociedades contemporâneas: métodos. 2. ed. São Paulo: Editora UNESP, 2010.

. Rituais de rebelião no sudeste da África. Série Tradução, v. 1, Brasília: DAN/UnB, 2011.

HERZFELD, Michael. Meaning and morality: a semiotic approach to evil eye accusations in a Greek village. American Ethnological Society, p. 560-574, 1981.

KANT DE LIMA, Roberto e PEREIRA, Luciana F. Pescadores de Itaipu: meio ambiente, conflito e ritual no litoral do Rio de Janeiro. Niterói, EDUFF, 1997.

LÉVY-BRUHL, Lucien. A mentalidade primitiva. São Paulo: Paulus, 2008.

MAGGIE, Yvonne.Guerra de orixá: um estudo de ritual e conflito. 3. ed. Rio de Janeiro: Jorge Zahar, 2001.

LOBÃO, Ronaldo. Cosmologias políticas do neocolonialismo: como uma política pública pode se transformar em uma política de ressentimento. Niterói: Editora da Universidade Federal Fluminense, 2010.

MAUSS, Marcel e HUBERT, Henri. Esboço de uma teoria geral da magia. In: Sociologia e antropologia. São Paulo: Cosac Naify, 2013.

MELLO, Marco Antonio da Silva e VOGEL, Arno. Gente das areias: história, meio ambiente e sociedade no litoral brasileiro. Maricá, RJ - 1975 A 1995. Niterói, EDUFF, 2004.

MOTA, Fabio Reis. Nem muito mar, nem muita terra. Nem tanto negro, nem tanto branco: uma discussão sobre o processo de construção da identidade da comunidade remanescente de quilombos na Ilha da Marambaia. 2003. $172 \mathrm{f}$. Dissertação (Mestrado em Antropologia) - Instituto de Ciências Humanas e Filosofia, Universidade Federal Fluminense, Niterói, 2003.

PEIRANO, Mariza G. S. A análise antropológica de rituais. In: PEIRANO, Mariza (org.). $O$ dito e o feito: ensaios de antropologia dos rituais. Rio de Janeiro: Relume Dumará: Núcleo de Antropologia da Política/UFRJ, 2002.

PESSANHA, Elina Gonçalves da Fonte. Os companheiros: trabalho e sociabilidade na pesca de Itaipu. Niterói: EDUFF, 2003.

POLANYI, Karl. A grande transformação: as origens da nossa época. 2. ed. Rio de Janeiro: Elsevier, 2012.

PUTNAM, Linda L. e WONDOLLECK, Julia M. Intractability: definitions, dimensions and distinctions. In. LEWICKI, Roy et al. Making sense of intractable environmental conflicts. Washington, DC: Island Press, 2003. 
SAHLINS, Marshall. Ilhas de histórias. Rio de Janeiro: Jorge Zahar Editor, 1990.

SILVA, Gláucia Oliveira da. Tudo que tem na terra tem no mar: a classificação dos seres vivos entre trabalhadores da pesca em Piratininga. Rio de Janeiro: Editora FUNARTE, 1989.

SIMMEL, Georg. A natureza sociológica do conflito. In: MORAES FILHO, Evaristo (org.). Simmel: sociologia. São Paulo: Ática, 1983.

TARDELLI, Gabriel Calil. Lugar de pescador: usos, apropriações e conflito em torno de um barracão de pesca na Praia de Piratininga - Niterói (RJ). 2017. 145f. Dissertação (Mestrado em Ciências Sociais) - Centro de Ciências Sociais, Pontifícia Universidade Católica do Rio de Janeiro, Rio de Janeiro, 2017.

TURNER, Victor. Dramas, campos e metáforas: ação simbólica na sociedade humana. Niterói: EDUFF, 2008.

DATA DE SUBMISSÃO: 30/01/2019

DATA DE APROVAÇÃO: 10/09/2019 